Scientia Agricola

http://dx.doi.org/10.1590/0103-9016-2015-0106

\title{
Sorption and desorption of indaziflam degradates in several agricultural soils
}

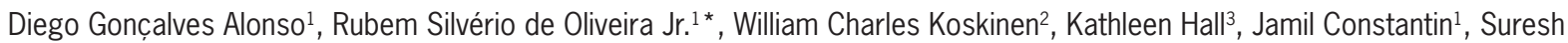 \\ Mislankar ${ }^{4}$
}

\author{
${ }^{1}$ State University of Maringá/Center for Advanced Studies in \\ Weed Research (NAPD) - Agronomy Dept., Av. Colombo, 579 \\ - 87020-900 - Maringá, PR - Brazil. \\ 2U.S. Department of Agriculture/Agricultural Research \\ Service, 439 Borlaug Hall, 1991 Upper Buford Circle - \\ 55108 - St. Paul, MN - USA. \\ 3University of Minnesota - Dept. of Soil, Water \& Climate, 439 \\ Borlaug Hall, 1991 Upper Buford Circle - 55108 - St. Paul, \\ MN - USA. \\ ${ }^{4}$ Bayer Crop Science LP, Environmental Fate and Exposure \\ Assessment, RTP, 2 TW Alexander Drive - 27709 - Research \\ Triangle Park, NC, USA. \\ *Corresponding author <rsojunior@uem.br>
}

Edited by: Silvia del Carmen Imhoff

Received March 13, 2015

Accepted July 20, 2015
ABSTRACT: Processes regulating pesticide fate in the environment are influenced by the physicochemical properties of pesticides and soils. Sorption and desorption are important processes as they regulate the movement of pesticides in soil. Although sorption-desorption is widely studied for herbicides, studies involving their metabolites in soil are scarce. Sorption and desorption of indaziflam metabolites (indaziflam-triazinediamine (FDAT), indaziflam-triazine-indanone (ITI) and indaziflam-carboxilic acid (ICA)) were investigated in six Brazilian (BRA) soils and three United States (USA) soils with different physicochemical properties. The Freundlich equation described sorption of the metabolites for all soils $\left(R^{2}>0.98 ; 1 / n \sim 1\right)$. Sorption order $\left(K_{f}\right)$ was ITI > ICA $>$ FDAT. Mean values of $K_{f}, 0 c$ were 453, 289, and 81 (BRA) and 444, 48, and 48 (USA) for metabolites ITI, ICA, and FDAT respectively. Desorption was hysteretic for all metabolites in all soils. These results suggest that these metabolites fall in the classification range of mobile to moderately mobile in soils.

Keywords: adsorption, hysteresis, metabolites, soil properties

\section{Introduction}

The fate and distribution of agrochemicals in the soil water environment are largely determined by sorption-desorption processes. Previous herbicide research has focused predominantly on the interaction of the parent compound with soil, while studies involving their metabolites are in short supply. Because data are unavailable for model input, it is often assumed that the metabolite sorption coefficient is equal to that of the parent compound. Studies on the metabolites of imidacloprid have demonstrated that this assumption can be inaccurate (Papiernik et al., 2006). For example, of three imidacloprid metabolites evaluated, two showed sorption higher than the parent compound and one lower (Cox et al., 1997; Papiernik et al., 2006). Alternatively, the idea that as a compound degrades, its byproducts are smaller and more polar, and, therefore, more mobile is also riddled with exceptions. The hydroxylated metabolites of atrazine (Clay and Koskinen, 1990) and florasulam (Krieger et al., 2000) show greater adsorption to soil than the parent compound. Experimental metabolite sorption data is, therefore, imperative for performing environmental assessments of herbicides. While information regarding herbicide metabolite behavior in soil is scarce overall, no data exist for the relatively new herbicide, indaziflam.

Indaziflam $\quad(N-[(1 R, 2 S)-2,3$-dihydro-2,6-dimethyl$1 H$-inden-1-yl]-6-[(1R)-1-fluoroethyl]-1,3,5-triazine-2,4diamine) is a herbicide recently approved for use in the United States and is in the process of being released in Brazil. The main transformation chemicals from the en- vironmental degradation of indaziflam are: indaziflamtriazine-indanone (ITI), indaziflam-carboxilic acid (ICA), indaziflam-hydroxyethyl, indaziflam-olefin, fluoroethyldiaminotriazine (FDAT), and fluoroethyltriazinanedione. Indaziflam, ITI and ICA are cleaved at the $\mathrm{N}$ bond to form FDAT (from the triazine portion) and unidentified minor compounds (from the indazyl portion). Residues are ultimately converted into bound residues and $\mathrm{CO}_{2}$ (Figure 1) (USEPA, 2010).

This study aimed to characterize sorption and desorption coefficients of three of the main metabolites of indaziflam (ITI, ICA and FDAT), for which there currently is no published information. Considering the diversity among the physicochemical properties of soils that can influence sorption-desorption, this study was carried out on a selection of tropical soils from Brazil (Oxisols) and glacial soils from the United States (Mollisols).

\section{Materials and Methods}

\section{Soils}

Nine various soils previously untreated with indaziflam were selected for this study: six Brazilian Oxisols and three United States Mollisols. Samples were collected from a depth of 0 to $10 \mathrm{~cm}$ depth, air-dried, and passed through a 2-mm sieve. Selected physicochemical properties of the soils appear in Table 1 . The hydrometer method was used to determine sand and clay contents and soil $\mathrm{pH}$ was measured in a 1:2 soil/deionized water mixture. The soil organic carbon (OC) content was ascertained by loss on ignition (Nelson and Sommers, 1982). 
Table 1 - Physicochemical properties of soils.

\begin{tabular}{|c|c|c|c|c|c|c|c|c|c|}
\hline \multirow{2}{*}{ Soil } & \multirow{2}{*}{ Origin (city, state) } & \multirow{2}{*}{ Soil classification ${ }^{1}$} & \multirow{2}{*}{$\mathrm{pH} \mathrm{H}_{2} \mathrm{O}$} & \multirow{2}{*}{$\mathrm{OC}^{2}$} & \multirow{2}{*}{ sand } & \multirow{2}{*}{ clay } & \multirow{2}{*}{ Text. $^{3}$} & \multicolumn{2}{|c|}{ Clay mineralogy ${ }^{4}$} \\
\hline & & & & & & & & Major & Minor \\
\hline & & & & 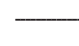 & $-\%$ & - & & & \\
\hline BRA1 & Marialva, PR & $\begin{array}{l}\text { Oxisol - Rhodic Hapludox } \\
\text { (Latossolo Vermelho distroférrico) }\end{array}$ & 6.0 & 1.60 & 27 & 65 & C & $\mathrm{C}, \mathrm{H}, 2: 1$ & Gib, MgH, An, Go, Qz, VHE \\
\hline BRA3 & Pres. Castelo Branco, PR & $\begin{array}{l}\text { Oxisol - Typic Hapludox } \\
\text { (Latossolo Vermelho distrófico) }\end{array}$ & 5.4 & 0.50 & 88 & 10 & LS & C, H, 2:1, Gib & Go, MgH, An, Qz \\
\hline BRA7 & Vilhena, RO & $\begin{array}{l}\text { Oxisol - Rhodic Hapludox } \\
\text { (Latossolo Vermelho distrófico) }\end{array}$ & 5.9 & 2.05 & 38 & 57 & C & C, H, Gib & Go, Qz \\
\hline BRA8 & Rio Verde, GO & $\begin{array}{l}\text { Oxisol - Rhodic Hapludox } \\
\text { (Latossolo Vermelho distrófico) }\end{array}$ & 6.2 & 2.17 & 39 & 59 & C & C, H, Gib & VHE \\
\hline BRA11 & Santa Maria, RS & $\begin{array}{l}\text { Oxisol - Arenic albaqualfs } \\
\text { (Planossolo Háplico eutrófico) }\end{array}$ & 6.0 & 1.06 & 62 & 17 & SL & C, $2: 1$ & VHE, Qz \\
\hline BRA12 & Barra do Bugres, MT & $\begin{array}{l}\text { Oxisol - Typic quartzipsaments } \\
\text { (Neossolo Quartzarênico órtico) }\end{array}$ & 6.5 & 0.61 & 92 & 7 & $S$ & C, Go & $\mathrm{H}, \mathrm{Qz}$ \\
\hline USA1 & Morris, MN (Footslope) & $\begin{array}{l}\text { Mollisol - Typic calciaquolls (Mary- } \\
\text { land sandy loam) }\end{array}$ & 8.1 & 2.18 & 56 & 19 & L & $n a^{5}$ & na \\
\hline USA2 & Morris, MN (Shoulder) & $\begin{array}{l}\text { Mollisol - Typic calciudolls } \\
\text { (Buse sandy clay loam) }\end{array}$ & 8.3 & 1.10 & 54 & 23 & L & na & na \\
\hline USA3 & Rosemount, MN & $\begin{array}{l}\text { Mollisol - Typic hapludolls (Wauke- } \\
\text { gan silt loam) }\end{array}$ & 6.0 & 2.52 & 33 & 15 & SL & na & na \\
\hline
\end{tabular}

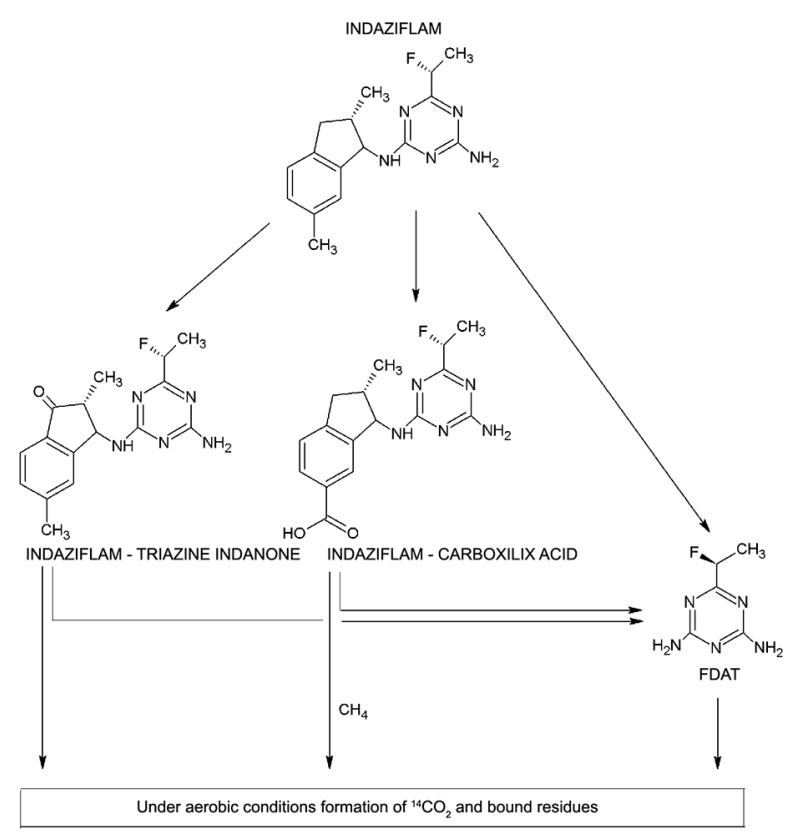

Figure 1 - Degradation pathway of indaziflam in the soil (USEPA, 2010).

\section{Chemicals}

Pure analytical standards of indaziflam-triazinediamine (FDAT) (6-[(1R)-1-fluoroethyl]-1,3,5-triazine-2,4-diamine), indaziflam-triazine-indanone (ITI) $(N$-[(1R,2S)-2,3-Dihydro-2,6-dimethyl-3-oxo- $1 H$-inden-iyl]-1,3,5-triazine-2,4-diamine) and indaziflam-carboxylic acid (ICA) $(2 S, 3 R)$-3-[[4-amino-6-[(1R)-1-fluoroethyl]1,3,5-triazin-2-yl]-amino]-2,3-dihydro-2-methyl- $1 H$ indene-5-carboxylic acid, and respective radioactive analytical standards, ${ }^{14} \mathrm{C}$-labeled (triazine-2,4- ${ }^{14} \mathrm{C}$ ) FDAT,
${ }^{14} \mathrm{C}$-labeled (indane-1-14 $\mathrm{C}$ ) ITI, and ${ }^{14} \mathrm{C}$-labeled (carboxyl$\left.{ }^{14} \mathrm{C}\right)$ ICA were graciously provided by Bayer Crop Science (Wuppertal, Germany). Solutions were prepared in $\mathrm{CaCl}_{2}(0.01 \mathrm{~N})$ to concentrations of $0.06,0.19,0.64$, and $1.91 \mu \mathrm{mol} \mathrm{L}^{-1}$ (FDAT), 0.03, 0.09, 0.3, and $0.95 \mu \mathrm{mol} \mathrm{L}^{-1}$ (ITI), and 0.03, 0.09, 0.31, and $0.92 \mu \mathrm{mol} \mathrm{L}^{-1}$ (ICA) with nonradioactive analytical standards. Radioactive analytical standards were added to provide $\sim 83 \mathrm{~Bq} \mathrm{~mL}^{-1}$ of radioactivity to solutions. Final solutions contained less than $0.4 \%$ methanol and were stored in foil-covered flasks in the dark at $4{ }^{\circ} \mathrm{C}$.

\section{Sorption}

Sorption studies were performed in triplicate using the batch equilibration method. Preliminary studies (Alonso et al., 2011) showed that to sorb 20-80\% of the initial chemical in solution on the soil (for greater analytical accuracy), a ratio of $4 \mathrm{~g}$ soil to $10 \mathrm{~mL}$ (4:10) solution was acceptable for the ITI metabolite, whereas for FDAT

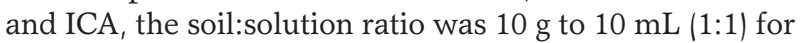
each sample. Glass centrifuge tubes (35-mL) with Teflon lined caps containing soil and radioactive solutions were mixed using a vortex mixer (30 s) and shaken for $24 \mathrm{~h}$ on a tabletop shaker $\left(20 \pm 2{ }^{\circ} \mathrm{C}\right)$ in the dark. Preliminary kinetic studies (Alonso et al., 2011) showed that equilibrium was reached in < $24 \mathrm{hrs}$. Sample tubes were then centrifuged (20 $\mathrm{min}$ at $370 \mathrm{~g}$ ) and $3-\mathrm{mL}$ of supernatant was removed from each sample for analysis. A 1-mL aliquot of the removed supernatant was mixed with $5 \mathrm{~mL}$ of a scintillation cocktail (EcoLite, cocktail, ICN Biomedicals, Costa Mesa, CA) and the concentration of ${ }^{14} \mathrm{C}$ of each metabolite in solution was determined by liquid scintillation counting with a Packard 1500 counter (Packard Instruments, Downer Grove, IL). The amount of chemical sorbed to the soil was calculated as the difference between the initial solution concentration and the supernatant concentration 
after equilibration. In preliminary studies, degradation of the chemical during equilibration was not observed, neither was sorption in blank tubes containing solution without soil. Data were fit to the Freundlich equation to obtain sorption coefficients.

\section{Desorption}

Immediately following the sorption experiments, desorption experiments were performed for each metabolite at the lowest and highest initial concentrations: 0.06 and $1.91 \mu \mathrm{mol} \mathrm{L}{ }^{-1}$ for FDAT, 0.03 and $0.95 \mu \mathrm{mol}$ $\mathrm{L}^{-1}$ for ITI, and 0.03 and $0.92 \mu \mathrm{mol} \mathrm{L}^{-1}$ for ICA on all nine soils. Desorption was determined by replacing the 3-mL aliquot of removed supernatant for sorption analysis with $3 \mathrm{~mL}$ of $0.01 \mathrm{~N} \mathrm{CaCl}_{2}$. The soils were then resuspended using a vortex mixer, shaken for $24 \mathrm{~h}$, and centrifuged. The supernatants were analyzed as previously described and again replaced with $\mathrm{CaCl}_{2}$. This was repeated for a total of three desorption steps. All studies were done in triplicate.

\section{Sorption and Desorption Model}

Sorption coefficients $K_{\mathrm{f}}$ and $1 / n$ were calculated from the slope and intercept of the log form of the Freundlich equation: $\log [C \mathrm{~s}]=\log K_{\mathrm{f}}+1 / n \log [\mathrm{Ce}]$; where $[C s]$ is the concentration $\left(\mu \mathrm{mol} \mathrm{kg}^{-1}\right)$ of the metabolite sorbed onto soil after equilibration and [Ce] is the metabolite concentration $\left.(\mu \mathrm{mol} \mathrm{L})^{-1}\right)$ after equilibration. Sorption coefficients were normalized to soil OC contents to give $K_{f-\text { oc }}\left(\mathrm{L} \mathrm{kg}^{-1}\right)$, where $K_{\mathrm{f}-\mathrm{oc}}=\left(K_{\mathrm{d}} / \% \text { OC }\right)^{*} 100$. The hysteresis coefficient, $H$, for the sorption-desorption isotherms was determined using the formula $H=\mid 1 /$ $\left.n_{\text {desorption }}\right) /\left(1 / n_{\text {sorption }}\right)$, where $1 / n_{\text {sorption }}$ and $1 / n_{\text {desorption }}$ are the Freundlich slopes from the sorption and desorption isotherms, respectively (Barriuso et al., 1994).

Sorption distribution coefficients $K_{\mathrm{d}}\left(\mathrm{L} \mathrm{kg}^{-1}\right)$, where $K_{\mathrm{d}}=[\mathrm{Cs}] /[\mathrm{Ce}]$, were also calculated for the lowest and highest initial solution concentrations and normalized to soil OC contents to give $K_{\text {oc }}\left(\mathrm{L} \mathrm{kg}^{-1}\right)$, where $K_{\text {oc }}=\left(K_{\mathrm{d}}\right)$ $\%$ OC) $* 100 . K_{\mathrm{d}}$ and $K_{\mathrm{oc}}$ values were used to compare sorption between soils at initial solution concentrations with sorption calculated after the third desorption step. The concentration of metabolite remaining in the $0.01 \mathrm{~N}$ $\mathrm{CaCl}_{2}$ solution after the third desorption step was taken as $\left[C_{\mathrm{e}}\right]$, and the concentration of metabolite sorbed, $\left[C_{\mathrm{s}}\right]$, was assumed to equal the initial concentration minus the amount remaining in the solution and the amount removed in the previous desorption steps.

\section{Statistical Analysis}

For each metabolite, Pearson Product Moment Correlation analyses were performed charting the sorption coefficients against selected soil physicochemical properties using the SigmaPlot (SysStat ${ }^{\circ}$ for Windows, Version 10). For all correlation analyses, soils were divided into two groups, tropical soils (BRA) and glacial soils (USA). Linear regression analyses were performed using the same software package.

\section{Results and Discussion}

\section{Sorption}

The empirical Freundlich equation described the sorption behavior of the metabolites FDAT (Table 2, Figure 2), ITI (Table 3, Figure 3), and ICA (Table 4, Figure 4) for all soils $\left(R^{2}>0.98\right)$. Average $1 / n$ values were 0.99 for FDAT, and 0.95 for ITI and ICA indicating sorption was minimally dependent on initial solution concentration. As $1 / n$ values did not differ significantly from one another, $K_{\mathrm{f}}$ values were used for comparisons. In general, the order of sorption magnitude for the indaziflam metabolites in the present study was FDAT $<$ ICA $<$ ITI. $K_{\mathrm{f}}$ values for FDAT, the least sorbed metabolite, were 0.14 to 3.0 in Oxisols and 0.63 to 0.85 in Mollisols. ICA $K_{\mathrm{f}}$ values of Oxisols ranged from 0.51 to 13.1 , whereas

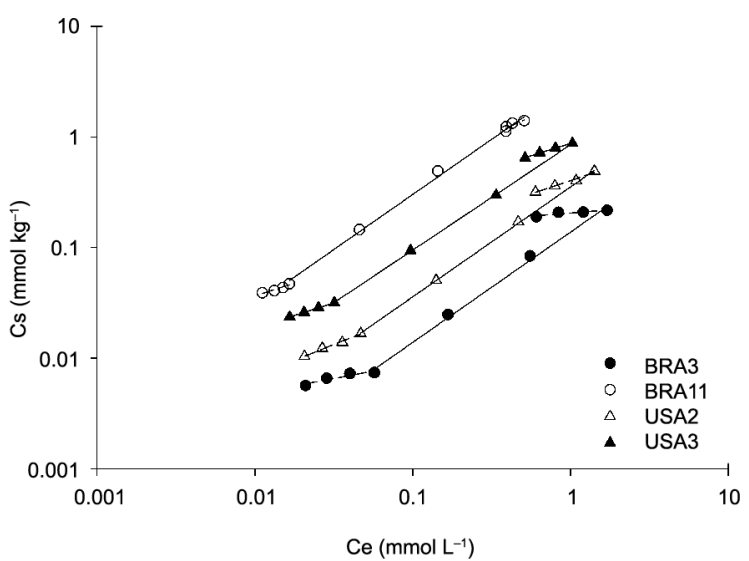

Figure 2 - Freundlich isotherm fit to describe sorption (solid symbols) and desorption (open symbols) of indaziflam-triazinediamine (FDAT) at concentrations of 0.06 and $1.91 \mu \mathrm{mol} \mathrm{L}^{-1}$ for soils BRA3, BRA11, USA2, and USA3.

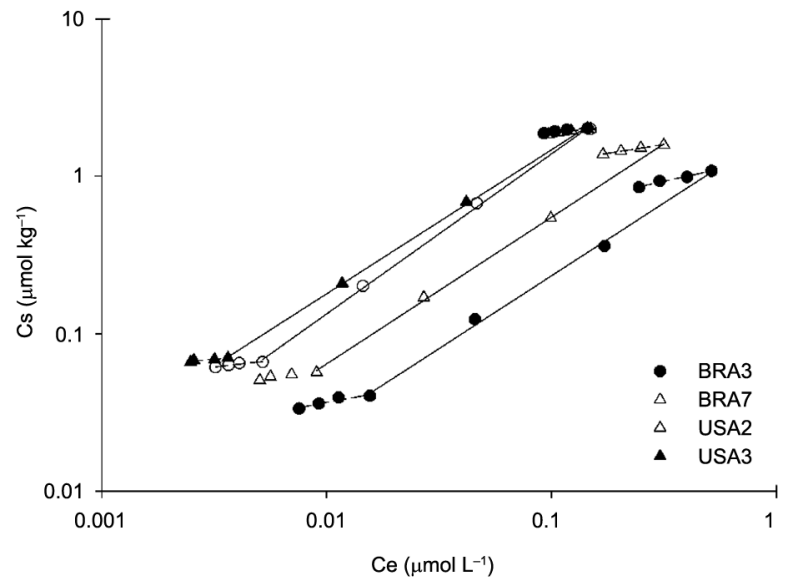

Figure 3 - Freundlich isotherms fit to describe sorption (solid symbols) and desorption (open symbols) of indaziflam-triazine-

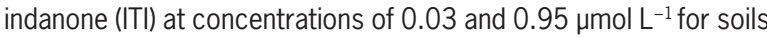
BRA3, BRA7, USA2, and USA3. 
Table 2 - Freundlich sorption parameters for indaziflam-triazinediamine (FDAT) metabolite of indaziflam for soils studied.

\begin{tabular}{|c|c|c|c|c|c|c|c|c|}
\hline Soil & $K_{f}$ & $K_{\mathrm{r}, \mathrm{oc}}$ & $1 / n$ sorption & $R^{2}$ & Init. Conc. Desorption & $1 / n$ desorption & $H$ & $K_{d \text { des } 3} / K_{d}$ \\
\hline & $-\mu \mathrm{mol}{ }^{(1-1-1}$ & $\mathrm{kg}^{-1}$ & & & $\mu \mathrm{mol} \mathrm{L^{-1 }}$ & & & \\
\hline \multirow[t]{2}{*}{ BRA 1} & $\begin{array}{c}0.93 \\
(0.93-0.94)^{\S}\end{array}$ & $\begin{array}{c}58 \\
(58-59)\end{array}$ & $0.99 \pm 0.0$ & 1.0 & 1.91 & 0.41 & 0.42 & 1.54 \\
\hline & & & & & 0.06 & 0.44 & 0.49 & 1.48 \\
\hline \multirow[t]{2}{*}{ BRA 3} & $\begin{array}{c}0.14 \\
(0.13-0.15)\end{array}$ & $\begin{array}{c}28 \\
(26-30)\end{array}$ & $1.0 \pm 0.04$ & 0.9963 & 1.91 & 0.12 & 0.12 & 2.38 \\
\hline & & & & & 0.06 & 0.26 & 0.27 & 2.08 \\
\hline \multirow[t]{2}{*}{ BRA 7} & $\begin{array}{c}1.18 \\
(1.16-1.19)\end{array}$ & $\begin{array}{c}57 \\
(57-58)\end{array}$ & $0.97 \pm 0.01$ & 0.9999 & 1.91 & 0.26 & 0.26 & 1.66 \\
\hline & & & & & 0.06 & 0.39 & 0.40 & 1.39 \\
\hline \multirow[t]{2}{*}{ BRA 8} & $\begin{array}{c}0.5 \\
(0.47-0.54)\end{array}$ & $\begin{array}{c}23 \\
(22-25)\end{array}$ & $1.0 \pm 0.04$ & 0.9975 & 1.91 & 0.44 & 0.44 & 1.62 \\
\hline & & & & & 0.06 & 0.44 & 0.44 & 1.57 \\
\hline \multirow[t]{2}{*}{ BRA 11} & $3.0(2.64-3.41)$ & $\begin{array}{c}283 \\
(249-322)\end{array}$ & $1.0 \pm 0.05$ & 0.9957 & 1.91 & 0.67 & 0.67 & 1.05 \\
\hline & & & & & 0.06 & 0.46 & 0.46 & 1.25 \\
\hline \multirow[t]{2}{*}{ BRA 12} & $\begin{array}{c}0.21 \\
(0.21-0.22)\end{array}$ & $\begin{array}{c}35 \\
(34-36)\end{array}$ & $1.02 \pm 0.02$ & 0.9996 & 1.91 & 0.29 & 0.28 & 2.05 \\
\hline & & & & & 0.06 & 0.29 & 0.28 & 2.05 \\
\hline \multirow[t]{2}{*}{ USA 1} & $\begin{array}{c}0.63 \\
(0.61-0.65)\end{array}$ & $\begin{array}{c}29 \\
(28-30)\end{array}$ & $0.98 \pm 0.01$ & 0.9997 & 1.91 & 0.44 & 0.45 & 1.54 \\
\hline & & & & & 0.06 & 0.45 & 0.46 & 1.52 \\
\hline \multirow[t]{2}{*}{ USA 2} & $\begin{array}{c}0.90 \\
(0.88-0.92)\end{array}$ & $\begin{array}{c}82 \\
(80-83)\end{array}$ & $0.99 \pm 0.01$ & 0.9998 & 1.91 & 0.48 & 0.49 & 1.51 \\
\hline & & & & & 0.06 & 0.56 & 0.56 & 1.42 \\
\hline \multirow[t]{2}{*}{ USA 3} & $\begin{array}{c}0.85 \\
(0.84-0.86)\end{array}$ & $\begin{array}{c}34 \\
(33-34)\end{array}$ & $0.95 \pm 0.01$ & 0.9999 & 1.91 & 0.44 & 0.46 & 1.48 \\
\hline & & & & & 0.06 & 0.45 & 0.47 & 1.43 \\
\hline
\end{tabular}

$\S$ Numbers in parentheses are confidence intervals $\left(K_{f}, K_{f, o c}\right)$ or standard deviations of the means $(1 / n)$.

Table 3 - Freundlich sorption parameters for indaziflam-triazine-indanone (ITI) metabolite of indaziflam for soils studied.

\begin{tabular}{|c|c|c|c|c|c|c|c|c|}
\hline Soil & $K_{f}$ & $K_{\mathrm{f}, \mathrm{cc}}$ & $1 / n$ sorption & $R^{2}$ & Init. Conc. desorption & $1 / n$ desorption & $H$ & $K_{\text {d des } 3} / K_{d}$ \\
\hline \multirow{3}{*}{ BRA 1} & $-\mu \mathrm{mol}{ }^{11}$ & $\mathrm{~kg}^{-1}$ & & & $\mu \mathrm{mol} \mathrm{L^{-1 }}$ & & & \\
\hline & $\begin{array}{c}10.0 \\
(7.34-13.61)^{\S}\end{array}$ & $\begin{array}{c}625 \\
(459-851)\end{array}$ & $0.95 \pm 0.08$ & 0.9853 & 0.95 & 0.05 & 0.06 & 1.97 \\
\hline & & & & & 0.03 & 0.02 & 0.02 & 2.29 \\
\hline \multirow[t]{2}{*}{ BRA 3} & $\begin{array}{c}1.96 \\
(1.79-2.14)\end{array}$ & $\begin{array}{c}392 \\
(358-428)\end{array}$ & $0.92 \pm 0.03$ & 0.9976 & 0.95 & 0.31 & 0.33 & 1.66 \\
\hline & & & & & 0.03 & 0.26 & 0.28 & 1.72 \\
\hline \multirow[t]{2}{*}{ BRA 7} & $\begin{array}{c}14.46 \\
(13.22-15.83)\end{array}$ & $\begin{array}{c}706 \\
(645-772)\end{array}$ & $1.02 \pm 0.02$ & 0.9989 & 0.95 & 0.18 & 0.18 & 1.42 \\
\hline & & & & & 0.03 & 0.15 & 0.15 & 1.51 \\
\hline \multirow[t]{2}{*}{ BRA 8} & $\begin{array}{c}4.26 \\
(4.02-4.52)\end{array}$ & $\begin{array}{c}196 \\
(185-208)\end{array}$ & $0.98 \pm 0.02$ & 0.9992 & 0.95 & 0.26 & 0.26 & 1.59 \\
\hline & & & & & 0.03 & 0.14 & 0.14 & 1.87 \\
\hline \multirow[t]{2}{*}{ BRA 11} & $\begin{array}{c}4.24 \\
(4.13-4.35)\end{array}$ & $\begin{array}{c}400 \\
(390-410)\end{array}$ & $0.94 \pm 0.01$ & 0.9998 & 0.95 & 0.50 & 0.53 & 1.24 \\
\hline & & & & & 0.03 & 0.44 & 0.46 & 1.17 \\
\hline \multirow[t]{2}{*}{ BRA 12} & $\begin{array}{c}2.46 \\
(2.32-2.60)\end{array}$ & $\begin{array}{c}403 \\
(381-425)\end{array}$ & $0.92 \pm 0.02$ & 0.9991 & 0.95 & 0.24 & 0.26 & 0.70 \\
\hline & & & & & 0.03 & 0.17 & 0.19 & 1.89 \\
\hline \multirow[t]{2}{*}{ USA 1} & $\begin{array}{c}9.19 \\
(8.25-10.24)\end{array}$ & $\begin{array}{c}422 \\
(378-470)\end{array}$ & $0.94 \pm 0.03$ & 0.9990 & 0.95 & 0.07 & 0.08 & 1.85 \\
\hline & & & & & 0.03 & 0.03 & 0.03 & 2.10 \\
\hline \multirow[t]{2}{*}{ USA 2} & $\begin{array}{c}4.72 \\
(4.48-4.96)\end{array}$ & $\begin{array}{c}429 \\
(408-451)\end{array}$ & $0.93 \pm 0.02$ & 0.9994 & 0.95 & 0.22 & 0.24 & 1.62 \\
\hline & & & & & 0.03 & 0.18 & 0.19 & 1.60 \\
\hline \multirow[t]{2}{*}{ USA 3} & $\begin{array}{c}12.14 \\
(12.60-12.71)\end{array}$ & $\begin{array}{c}482 \\
(460-504)\end{array}$ & $0.91 \pm 0.01$ & 0.9997 & 0.95 & 0.16 & 0.18 & 1.45 \\
\hline & & & & & 0.03 & 0.13 & 0.14 & 1.38 \\
\hline
\end{tabular}

$\S$ Numbers in parentheses are confidence intervals $\left(K_{\mathrm{f}}, K_{\mathrm{f}, \mathrm{c}}\right)$ or standard deviations of the means $(1 / n)$.

$K_{\mathrm{f}}$ values for Mollisols ranged from 0.43 to 1.56 . ITI $K_{\mathrm{f}}$ values in Oxisols ranged from 1.96 to 14.5 and from 4.72 to 12.1 in Mollisols. All metabolites showed much lower sorption than the parent compound in the cor- responding soil (Alonso et al., 2011), which supports the general observation that degradates are more polar and soluble than parent chemicals, and subsequently less sorbed. 
Table 4 - Freundlich sorption parameters for indaziflam-carboxilic acid (ICA) metabolite of indaziflam for soils studied.

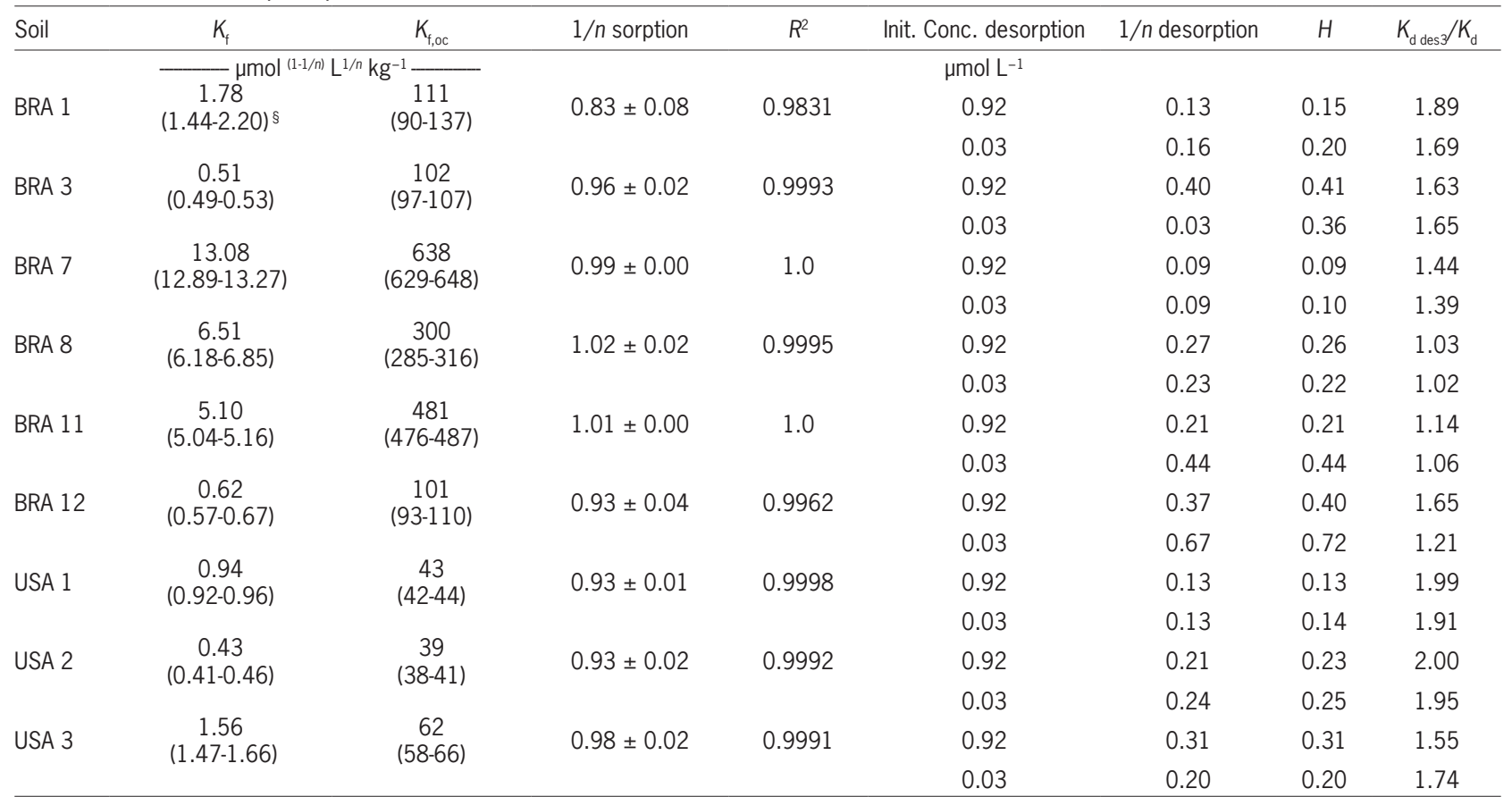

$\S$ Numbers in parentheses are confidence intervals $\left(K_{f}, K_{f, o c}\right)$ or standard deviations of the means $(1 / n)$.

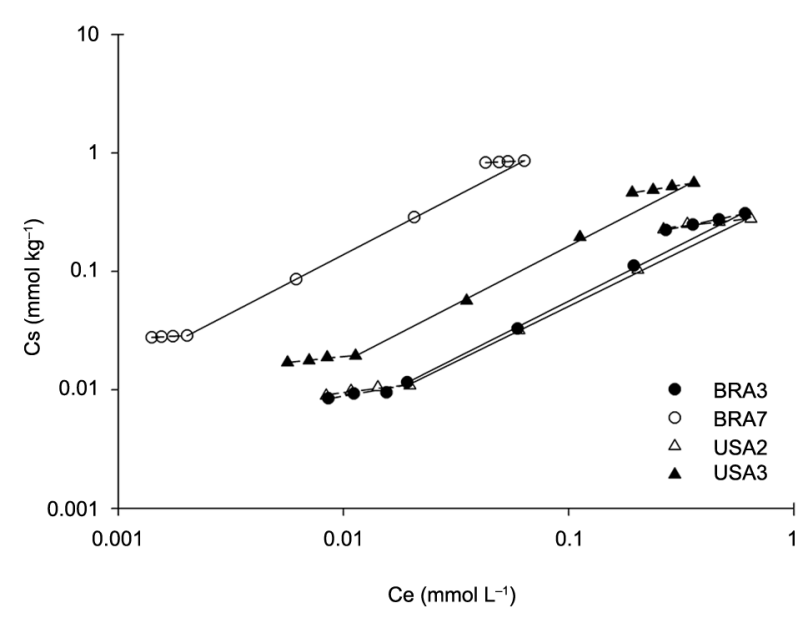

Figure 4 - Freundlich isotherms fit to describe sorption (solid symbols) and desorption (open symbols) of indaziflam-carboxylic acid (ICA) at concentrations of 0.03 and $0.92 \mu \mathrm{mol} \mathrm{L-1}$ for soils BRA3, BRA7, USA2, and USA3.

Sorption of FDAT was lower as compared to indaziflam, presumably due to differences in hydrophobic interactions. Using a theoretical pKa for FDAT of 4.10 (Chemaxon, 2014), a higher \%age of cationic molecules would be expected as compared to indaziflam $(\mathrm{pKa}=$ 3.5), and greater sorption. However, the pKa is not the only factor that affects sorption. There was no correlation $(p<0.05)$ between low FDAT $K_{\mathrm{f}}$ values and the physicochemical properties (ie. $\mathrm{pH}$ and \%age clay) of the soils. Although there was no significant correlation between $K_{\mathrm{f}}$ and OC, the normalization of $K_{\mathrm{f}}$ for organic carbon $(\% \mathrm{OC})$ reduced the variability of sorption coefficients. Variation range in $K_{\mathrm{f}, \mathrm{oc}}$ was $\sim 12 \mathrm{x}$ in contrast to the $\sim 21 \mathrm{x}$ variation for $K_{\mathrm{f}}$.

The ICA $K_{\mathrm{f}}$ values of Oxisols had significant positive correlation $(p<0.05)$ with \% OC $\left(\mathrm{r}=0.76^{* *}\right)$, and an equation describing $K_{\mathrm{f}}$ as a function of \% OC was calculated where $K_{\mathrm{f}}=-2.1738+5.0867 \%$ OC $\left(R^{2}=0.57\right)$. ICA sorption was not correlated with clay content or $\mathrm{pH}$ of these soils. In the Mollisols, significant negative correlations $(p<0.05)$ were observed for ICA $K_{\mathrm{f}}$ values with $\mathrm{pH}\left(\mathrm{r}=-0.93^{* *}\right)$ and clay content $(\mathrm{r}=-0.99 * *)$. Linear equations describing $K_{\mathrm{f}}$ as a function of soil $\mathrm{pH}\left(K_{\mathrm{f}}=\right.$ $\left.4.0454-0.411 \mathrm{pH}, R^{2}=0.87\right)$, clay contents $\left(K_{\mathrm{f}}=3.6604\right.$ $-0.1413 \%$ Clay, $\left.R^{2}=0.99\right)$, and \% OC $\left(K_{\mathrm{f}}=-0.4103+\right.$ $0.7174 \%$ OC, $\left.R^{2}=0.88\right)$ were calculated. Although not significant, the normalization of $K_{\mathrm{f}}$ or $K_{\mathrm{d}}$ for organic carbon content reduced sorption variability between soils by approximately half, from $\sim 30$ to $\sim 16$. The low ICA sorption is presumably related to the anionic character of the metabolite at the $\mathrm{pH}$ of the suspensions. The anionic acid group is repelled by the negative charge of Oxisols, or weakly retained as the molecular species by most soil and sediment components in glacial soils (FAO, 2000). According to calculations, pKa varied from 3.70 to 4.36 , depending on the group, triazine ring or the acid group (Chemaxon, 2014).

ITI $K_{\mathrm{f}}$ was positively correlated $(p<0.05)$ with organic carbon $\left(\%\right.$ OC) $\left(\mathrm{r}=0.68^{*}\right)$ and with clay content (\% Clay) $\left(\mathrm{r}=0.74^{*}\right)$ of the Oxisols. Linear equations describing $K_{\mathrm{f}}$ as a function of carbon content $\left(K_{\mathrm{f}}\right.$ 
$=-0.0171+4.6889 \%$ OC, $\left.R^{2}=0.46\right)$ and $K_{\mathrm{f}}$ as a function of clay content $\left(K_{\mathrm{f}}=1.4215+0.1342 \%\right.$ Clay, $R^{2}$ $=0.54)$ were calculated. The poor fit observed for both cases is directly related to low sorption by soil BRA8. Although its physicochemical characteristics are similar to soil BRA7, its $K_{\mathrm{f}}$ was $\sim 3$ times lower. Similar behavior was observed for the sorption of the parent compound (indaziflam) for the same soil (Alonso et al., 2011). It is surprising that there was no correlation between sorption and $\mathrm{pH}$. The theoretical $\mathrm{pKa}$ for triazine indanone is 4.10 (Chemaxon, 2014), and the \%age cationic molecules at a given $\mathrm{pH}$ would be expected to contribute to sorption. However, as was mentioned above, the pKa is not the only factor that affects the sorption.

For the three Mollisols studied, there were significant incidences of correlation between the ITI Freundlich sorption coefficients and soil $\mathrm{pH}, \% \mathrm{OC}$ and \% clay. The $\mathrm{pH}\left(\mathrm{r}=-0.85^{* *}\right)$ and clay content $(\mathrm{r}=-0.99 * *)$ were negatively correlated with $K_{\mathrm{f}}$, whereas the organic carbon content correlated positively with the $K_{\mathrm{f}}$ for these soils $\left(\mathrm{r}=0.98^{* *}\right)$. Linear equations describing $K_{\mathrm{f}}$ as a function of soil $\mathrm{pH}\left(K_{\mathrm{f}}=27.2005-2.48 \mathrm{pH}, R^{2}=0.72\right)$, clay contents $\left(K_{\mathrm{f}}=26.3058-0.9275 \%\right.$ Clay, $\left.R^{2}=0.99\right)$, and \% OC $\left(K_{\mathrm{f}}=-0.9101+4.9621 \%\right.$ OC, $\left.R^{2}=0.97\right)$ were significant. The negative correlation observed between $K_{\mathrm{f}}$ and clay content is possibly a result of the positive correlation between $K_{\mathrm{f}}$ and the organic carbon content of these soils overshadowing the contribution of the clay. The normalization of both $K_{\mathrm{f}}$ and $K_{\mathrm{d}}$ for \% OC $\left(K_{\mathrm{f}, \mathrm{oc}}\right)$ reduced the coefficients' range of variability from $\sim 7.5 \mathrm{x}$ to $\sim 4 \mathrm{x}$.

When the sorption of metabolites is very low, such as is the case with FDAT, the chemical properties of the soil will bear little or no relation to the mobility of the compound. On the other hand, when the metabolite presents higher sorption, the main chemical property contributing to increased sorption is the carbon content, which showed significant correlation with the sorption of these compounds in most cases. This correlation is reiterated by the fact that the normalization of $K_{\mathrm{f}}$ and $K_{\mathrm{d}}$ to carbon contents $K_{\mathrm{f}, \mathrm{oc}}$ and $K_{\mathrm{oc}}$ respectively, reduced the variability between the coefficients.

The main soil variable that was negatively correlated with the sorption of metabolites was $\mathrm{pH}$. The inverse relationship between $\mathrm{pH}$ and sorption suggests that the compounds may be partially ionized in the soil solution. ITI and FDAT have N-groups, which may be protonated at low $\mathrm{pH}$, while ICA may be dissociated at high $\mathrm{pH}$. On the other hand, compounds that are not ionized in the soil tend not to show any correlation between sorption and $\mathrm{pH}$.

The inconsistent effects of clay content on the sorption of metabolites, showing both positive (Oxisols) and negative correlation (Mollisols), suggests that the influence of the organic fraction and $\mathrm{pH}$ of these soils are the main characteristics affecting sorption. In Mollisols organic carbon was inversely related to clay contents and $\mathrm{pH}$. Therefore, sorption increased with the increase in \% OC and the decrease in $\mathrm{pH}$, which resulted in apparent negative correlation between $K_{\mathrm{f}}$ and the clay fraction of these soils. Negative correlation between $K_{\mathrm{f}}$ and the clay fraction of these soils was also observed for the parent compound (indaziflam) (Alonso et al., 2011).

\section{Desorption}

Desorption of the three metabolites was found to be hysteretic for all soils studied, $1 / n_{\text {desorption }}<1 / n_{\text {sorption }}$ (Tables 2, 3 and 4). Figures 2, 3 and 4 show representative desorption isotherms of the metabolites in four soils at the lowest and the highest initial concentrations used in the study. Hysteresis coefficients, $H$, ranged from 0.27 to 0.49 (in $0.06 \mu \mathrm{mol} \mathrm{L}^{-1}$ ) and from 0.12 to 0.67 (in 1.91 $\mu \mathrm{mol} \mathrm{L})^{-1}$ ) for Oxisols, and from 0.46 to 0.56 (in 0.06 $\mu \mathrm{mol} \mathrm{L}{ }^{-1}$ ) and from 0.45 to 0.49 (in $1.91 \mu \mathrm{mol} \mathrm{L}{ }^{-1}$ ) for Mollisols (Table 2).

It is difficult to ascribe the degree of hysteresis to a particular soil property. Although $H$ showed a significant positive correlation $(p<0.05)$ with Oxisol $K_{\mathrm{f}}$ values $(\mathrm{r}=$ $0.71^{* *}$ ) (described by the equation $H=0.2784-0.0998$ $K_{\mathrm{f}} R^{2}=0.50$ ), no correlation was found between $H$ and the physicochemical characteristics of the Oxisols in this study. In contrast, in the Mollisols negative correlation was observed between $H$ and \% OC $\left(\mathrm{r}=-0.78^{* *}\right)$ and positive correlation between $H$ and \% Clay $\left(\mathrm{r}=0.66^{* *}\right)$ and between $H$ and $K_{\mathrm{f}}\left(\mathrm{r}=0.61^{*}\right)$. Multiple correlation was described by the following linear equations: $H=$ $0.5739-0.0477 \%$ OC, $R^{2}=0.60 ; H=0.3392+0.0075$ $\%$ Clay, $R^{2}=0.43$; and $H=0.3272+0.1947 K_{\mathrm{f}} R^{2}=$ 0.38 . No correlation was found between $H$ and $\mathrm{pH}$ of the Mollisols.

ITI hysteresis coefficients $(H)$ for Oxisols ranged from 0.02 to 0.46 (in $0.03 \mu \mathrm{mol} \mathrm{L}^{-1}$ ) and from 0.06 to 0.53 (in $0.95 \mu \mathrm{mol} \mathrm{L}{ }^{-1}$ ). For Mollisols, $H$ ranged from 0.03 to 0.13 (in $0.03 \mu \mathrm{mol} \mathrm{L}{ }^{-1}$ ) and from 0.08 to 0.24 (in $0.95 \mu \mathrm{mol} \mathrm{L}^{-1}$ ) (Table 2). There was significant negative correlation $(p<0.05)$ between $H$ and Oxisol clay contents $\left(\mathrm{r}=-0.67^{* *}\right)$, described by the equation $H=$ $0.3782-0.0039 \%$ Clay, $R^{2}=0.45$. No correlation was found between $H$ and $K_{\mathrm{f}}$ or between $H$ and the other reported characteristics of the soils.

ICA hysteresis coefficients, $H$, ranged from 0.10 to 0.72 (in $0.03 \mu \mathrm{mol} \mathrm{L}^{-1}$ ) and from 0.09 to 0.41 (in $0.92 \mu \mathrm{mol}$ $\mathrm{L}^{-1}$ ) for Oxisols and from 0.14 to 0.25 (in $0.03 \mu \mathrm{mol} \mathrm{L}^{-1}$ ) and 0.13 to 0.31 (in $0.92 \mu \mathrm{mol} \mathrm{L}^{-1}$ ) for Mollisols. There was significant negative correlation $(p<0.05)$ between $H$ and \% OC $\left(\mathrm{r}=-0.74^{* *}\right), \%$ Clay $\left(\mathrm{r}=-0.76^{* *}\right)$, and $K_{\mathrm{f}}(\mathrm{r}$ $\left.=-0.63^{*}\right)$ for Oxisols, described by the following equations: $H=0.5537-0.1930 \%$ OC, $R^{2}=0.54 ; H=0.4865$ - $0.0053 \%$ Clay, $R^{2}=0.58$; and $H=0.4102-0.0247 K_{\mathrm{f}} R$ ${ }^{2}=0.40$. No correlation was found between $H$ and Oxisol pHs, nor was correlation found between $H$ and the physicochemical characteristics or $K_{\mathrm{f}}$ of Mollisols.

\section{Potential Mobility}

As a result of the lower sorption of the FDAT, ITI, and ICA metabolites compared to the parent compound, 
it is expected that their mobility will be higher than indaziflam. Based on the criteria established by the Food and Agriculture Organization of the United Nations (FAO) (FAO, 2000), FDAT $K_{\mathrm{f}-\mathrm{oc}}$ variation found in this study (Table 2), from 23 to $283 \mathrm{~L} \mathrm{~kg}^{-1}$ for tropical Oxisols and from 29 to $82 \mathrm{~L} \mathrm{~kg}^{-1}$ for glacial Mollisols, would be classified as FDAT as mobile in all soils studied except BRA11, in which it is considered moderately mobile. Based on $K_{\text {f-oc }}$ values (Table 3), ITI would be classified as moderately mobile in Oxisols $\left(K_{\mathrm{f}-\mathrm{oc}}=196-706 \mathrm{~L} \mathrm{~kg}^{-1}\right)$ and Mollisols $\left(K_{\mathrm{f}-\mathrm{oc}}=422-482 \mathrm{~L} \mathrm{~kg}^{-1}\right)$. ICA $K_{\mathrm{f}-\mathrm{oc}}$ values for Oxisols ranged from 101 to $638 \mathrm{~L} \mathrm{~kg}^{-1}$ and from 39 to 62 $\mathrm{L} \mathrm{kg}^{-1}$ for Mollisols (Table 3). Thus, the metabolite ICA would be classified as mobile to moderately mobile in Oxisols, and considered mobile in Mollisols (FAO, 2000).

Although sorption initially regulates soil-pesticide interactions, desorption also influences the potential mobility of these molecules and the risk of environmental contamination. Desorption represents the magnitude of the sorbed fraction that can return to the solution by reaching a new equilibrium. This typically occurs when a portion of the chemical initially present in solution is shifted in the soil profile or removed by adsorption, degradation, leaching, or volatilization. Therefore, to fully understand compound availability as a function of time, it is necessary to account for the desorbed fraction reentering the solution.

Desorption of the three metabolites is hysteretic, which means it does not occur to the same degree as sorption, $1 / n_{\text {sorption }}>>1 / n_{\text {desorption' }}$ and a large portion of sorbed metabolites is not easily desorbed or is desorbed slowly. Desorption hysteresis is caused by a variety of mechanisms for a large number of herbicide-soil systems (Wauchope et al., 2002). Weber et al. (1998) suggest that hysteresis can most likely be attributed to slow desorption and retention of sorbed molecules within highly condensed organic matrices. The highest coefficients of hysteresis were found for FDAT, indicating that along with being the least sorbed, this metabolite also has the highest desorption potential among those studied as a result of being partially protonated in the soil solution. The FAO mobility classification system (FAO, 2000) does not take this desorption hysteresis into account. Because the hysteretic behavior of chemicals reduces their mobility, the potential of contamination is likely overestimated.

A variety of transport models have been used to predict the potential leaching depth of a chemical in soil. The sorption coefficient, $K_{d^{\prime}}$ is the most commonly used retardation factor and the depth of leaching is directly proportional to the magnitude of $K_{d}$. This coefficient does not take into account hysteresis, if it occurs during desorption. For FDAT, use of the sorption $K_{d}$ would overpredict the depth of leaching by a factor of 1.5 to 2 as compared to using the sorption coefficients for the third desorption equilibration $\left(K_{d-\text { des }}\right)$ as indicated by the $K_{d \text {-des }} / K_{d}$ ratio (Table 2). Similarly, depending on the soil, potential depth of leaching could be overestimated by a factor of 2 for both ITI and ICA.
The evaluation of the potential leaching of these metabolites to ground water may vary according to environmental conditions, particularly with regard to their persistence in the soil. The more persistent these chemicals are, the greater the likelihood of them becoming major contaminants. Thus, complementary studies to determine the half-life of these compounds in the soil should be carried out with the aim of fully understanding their potential to become contaminants.

In summary, the three metabolites showed distinct behavior in terms of sorption in the soil, which suggests that they should be treated as isolated molecules. The three compounds are less sorbed than the parent compound, which indicates that they have a higher leaching potential in the soil, especially in those with low carbon content and high $\mathrm{pH}$. Hysteresis was observed in desorption experiments indicating an imbalance in the sorption-desorption process, which may signify the presence of strongly sorbed fractions and the formation of bound residues.

\section{Acknowledgments}

We thank CNPq and CAPES (Brazil) for financial support for this research. We also thank Bayer for supplying the analytical and radioactive materials; Luis Ávila (UFPel, RS), Hugo Dan (FESURV, GO), and Miriam Inoue (UNEMAT, MT) for their help in collecting soil samples.

\section{References}

Alonso, D.G.; Koskinen, W.C.; Oliveira Jr., R.S.; Constantin, J.; Mislankar, S. 2011. Sorption-desorption of indaziflam in selected agricultural soils. Journal of Agricultural and Food Chemistry 59: 13096-13101.

Barriuso, E.; Laird, D.A.; Koskinen, W.C.; Dowdy, R.H. 1994. Atrazine desorption from smectites. Soil Science Society of America Journal 58: 1632-1638.

ChemAxon. Physico-chemical property predictors. Available at: https://www.chemaxon.com/products/calculator-plugins/ property-predictors/ [Accessed Mar. 6, 2015]

Clay, S.; Koskinen, W.C. 1990. Adsorption and desorption of atrazine, hydroxyatrazine, and S-glutathione atrazine on two soils. Weed Science 38: 262-266.

Cox, L.; Koskinen, W.C.; Yen, P.Y. 1997. Sorption-desorption of imidacloprid and its metabolites in soils. Journal of Agricultural and Food Chemistry 45: 1468-1472.

Food and Agriculture Organization [FAO]. 2000. Assessing Soil Contamination: A Reference Manual. FAO, Rome, Italy.

Krieger, M.; Pillar, F.; Ostrander, J. 2000. Effect of temperature and moisture on the degradation and sorption of florasulam and 5-hydroxyflorasulam in soil. Journal of Agricultural and Food Chemistry 48: 4757-4766.

Nelson, D.W.; Sommers, L.E. 1982. Total carbon, organic carbon and organic matter. p. 539-579. In: Page, A.L.; Miller, R.H.; Keeney, D.R., eds. Methods of soil analysis: chemical and microbiological properties. SSSA, Madison, WI, USA. 
Papiernik, S.K.; Koskinen, W.C.; Cox, L.; Rice, P.J.; Clay, S.A.; Werdin-Pfisterer, N.R.; Norberg, K.A. 2006. Sorption-desorption of imidacloprid and its metabolites in soil and vadose zone materials. Journal of Agricultural and Food Chemistry 54: 8163-8170.

United States Environmental Protection Agency [USEPA]. 2010. Environmental Fate and Ecological Risk Assessment for the Registration of Indaziflam. USEPA, Washington, DC, USA.

Wauchope, R.D.; Yeh, S.; Linders, J.B.H.J.; Kloskowski, R.; Tanaka, K.; Rubin, B.; Katayama, A.; Kördel, W.; Gerstl, Z.; Lane, M.; Unsworth, J.B. 2002. Pesticide soil sorption parameters: theory, measurement, uses, limitations and reliability. Pest Management Science 58: 419-445.
Weber Jr., W.J.; Huang, W.; Yu, H. 1998. Hysteresis in the sorption and desorption of hydrophobic organic contaminants by soils and sediments. 2. Effects of soil organic matter heterogeneity. Journal of Contaminant Hydrology 31: 149-165. 